\title{
CES 2018
}

Dear Reader,

Byton (standing for bytes on wheels) is a new brand of electric vehicle manufactured by the promising Chinese startup Future Mobility. The first close-to-production prototype of the vehicle will be presented at the Consumer Electronics Show (CES) in 2018. "We're essentially a consumer electronics enterprise, and not an automobile manufacturer in the traditional sense," says Byton CEO Carsten Breitfeld in anticipation of the event. The former Head of Development for the BMW i8 is using connectivity and recreational appeal to position Future Mobility.

There's no interest in the classic vehicle at the CES in Las Vegas - in any case, not on the part of the visitors hoping to catch a glimpse of the future. Even the keynote addresses given by representatives of German manufacturers at the CES in recent years have focused on highly automated driving and high-performance connectivity. In 2017, it was the semiconductor manufacturer Nvidia that was in the spotlight. In 2018, among others, Lyft, the US- based transportation networking company, will be opening the trade fair.

The CES succeeds at what the IAA attempted only half-heartedly this year, namely, to shift the focus away from the classic vehicle and to the latest developments in the industry, including new business models such as seamless intermodal transportation and the key technologies that are necessary for it. This is an area in which the success of other Germany-based exhibition venues has also been marginal. The organisers of the CeBIT, for instance, are considering it. At this year's Electronics in Vehicles (ELIV) exhibition, Uwe Michael put it this way: "In the meantime, we've become IT and software engineers." The Head of Electronics at Porsche and ELIV Conference Director issued the following claim: "When it comes to conferences, our exhibition can be described as the German CES.” Refer to page 60 for a look at the conference report.

Read our interview with Helmut Matschi on page 24 to learn the extent to which German suppliers have successfully established themselves at the CES in recent years. Matschi, Executive Board Member at Continental, has played an active role at the exhibition in Las Vegas for the last ten years. Indeed, the company won a CES Innovation Award last year and Matschi will be the recipient of no fewer than three awards in 2018.

ATZelektronik presents this latest issue three weeks before the CES. In addition to the above-mentioned advance announcements, it is not for nothing that the cover story is devoted to semiconductors. This is because semiconductor tech is one of those key technologies today and is just as important to the automobile industry as it is to the consumer electronics industry.

I wish you a merry Christmas, a happy New Year 2018 and a safe journey to Las Vegas.
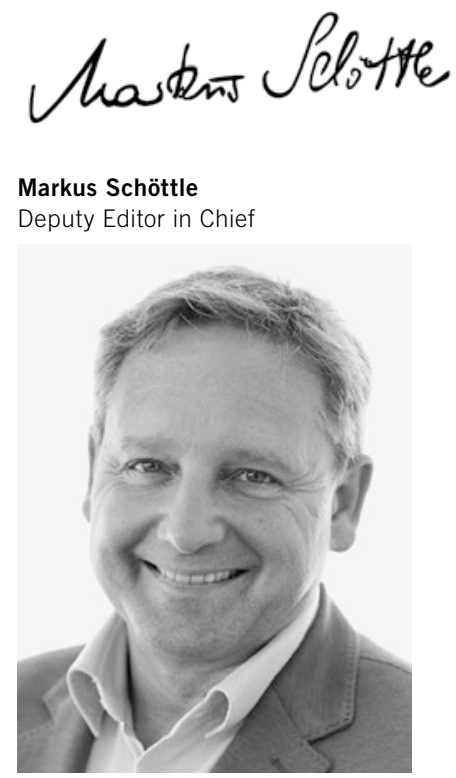